\section{G247 NON-INVASIVE HAEMOGLOBIN MEASUREMENTS FOR ASSESSING ANAEMIA IN KENYAN SCHOOL CHILDREN AS PART OF AN INTEGRATED SCHOOL HEALTH AND NUTRITION PROGRAMME}

J Bogie, B Eder, D Magnus. School of Medicine, University of Bristol, Bristol, UK

\subsection{6/archdischild-2015-308599.240}

Background Anaemia in school children is associated with impaired cognition and poor academic performance. In western Kenya around $20 \%$ of school-aged children are anaemic due to dietary insufficiencies, helminth infections and malaria. There is a need to find field-appropriate and cost-effective methods to assess anaemia in rural populations.

Method A comprehensive school health and nutrition programme was delivered to 3552 children in rural Western Kenya. Using a non-invasive Masimo-Pronto 7 device haemoglobin levels were measured biannually in a randomly selected sample of children. Consent was obtained from the schools and parents.

Results A total of 2538 haemoglobin measurements were made over the three-year pilot. Non-invasive haemoglobin measurements were easily performed by staff and well tolerated by children. Anaemia was defined as haemoglobin of less that $12 \mathrm{~g} / \mathrm{dl}$. At baseline $26.9 \%$ of children were anaemic Preliminary analysis of the first round of data collection showed a significant reduction in anaemia (OR 0.25 95\% CI 0.16-0.40 p $=<0.001$ ).

Discussion Non-invasive haemoglobin measuring is relatively unused in global health work despite evidence that it produces results comparable to serum testing. It is non-invasive, well tolerated by children, cheaper and simple to use. This project has shown the potential for using non-invasive haemoglobin measuring in complex health interventions and has been able to demonstrate an improvement in levels of anaemia over the first year of the pilot.

Conclusion Non-invasive haemoglobin measuring is feasible in the assessment of child health in low resource settings and will help in the evaluation of child health programmes.

\section{G248 LONG TERM SURVIVAL OF CHILDREN FROM A CLUSTER RANDOMISED CONTROLLED TRIAL OF WOMEN'S PARTICIPATORY GROUPS IN MAKWANPUR DISTRICT, NEPAL}

${ }^{1} \mathrm{M}$ Heys, ${ }^{2} \mathrm{DS}$ Manandhar, ${ }^{1} \mathrm{D}$ Osrin, ${ }^{2} \mathrm{KM}$ Tumbahangphe, ${ }^{2} \mathrm{~A}$ Sen, ${ }^{2} \mathrm{~B}$ Shrestha, ${ }^{2}$ DK Shrestha, ${ }^{2}$ RK Adhikari, ${ }^{2} \mathrm{~B}$ Budhathoki, ${ }^{1} \mathrm{~A}$ Costello. ${ }^{1}$ Institute of Global Health, University College London, London, UK; ${ }^{2}$ Mother and Infant Research Activities (MIRA), Nepal

\subsection{6/archdischild-2015-308599.241}

Background Women's groups practicing a participatory action learning approach (WPGs) to addressing issues around pregnancy, childbirth and newborn and child health have been shown in a number of trials in low income countries and on their meta-analysis to significantly reduce maternal and neonatal mortality. ${ }^{1}$ Their long term impact on survival has never been explored.

Aims To assess the long term impact of exposure to WPGs on maternal and child mortality in participants of the first cRCT of WPGs in Makwanpur District, rural Nepal (2001-2003). ${ }^{2}$

Methods Outcome data were collected by interview from the mother or the household head or from wider family members or neighbours where the family had moved. Analysis was carried out on an intention to treat basis using the a priori analysis plan in the original trial. ${ }^{2}$ Sensitivity analyses were performed using individual and cluster level comparison of person-years.

Results A total of 5824 mothers and 6078 children were alive 4 weeks postpartum (Figure 1). Reliable outcome data were available for $74.2 \%(4321)$ and $72.5 \%(4406)$ and probable outcomes for a further $24.8 \%$ (1452) and 26.8\% (1630) of mothers and children respectively. On individual analysis, children born into the intervention clusters had 32\% reduced risk of mortality after 4 weeks of age up to age of follow-up compared to those born into the control clusters (Table 1; Odds ratio (OR): 0.68 , confidence interval (CI): $0.51,0.92)$. Multilevel modelling adjusting for the effects of clustering and pairing of clusters showed a similar effect size, (OR: 0.69 CI: 0.49, 0.96; Table 1). Analyses using child mortality rates per person years are more conservative and the effect size smaller and non-statistically significant (however, this method does not take into account pairing of clusters, nor variation in size of clusters, Table 3) Fewer women in the intervention clusters died than control clusters, but the difference was not statistically significant. (Figure 1, Table 2).

Conclusion Our findings suggest there are long term survival benefits for children of WPGs beyond the neonatal period. Long term follow-up of other trials of WPGs are warranted.

\section{REFERENCES}

1 Prost A, Colbourn T, Seward N, et al. Women's groups practising participatory learning and action to improve maternal and newborn health in low-resource settings: a systematic review and meta-analysis. Lancet 2013;381:1736-46

2 Manandhar DS, Osrin D, Shrestha BP, et al. Effect of a participatory intervention with women's groups on birth outcomes in Nepal: cluster-randomised controlled trial. Lancet 2004;364:970-9

\section{G249 ARE CITIES GOOD FOR CHILD HEALTH? THE CASE OF THE URBAN POOR IN MUMBAI, INDIA AND LAGOS, NIGERIA}

LC Clemans. School of Medicine, University of Manchester, Manchester, UK

10.1136/archdischild-2015-308599.242

Conclusion The urban poor are chronically underrepresented in both health data collection and urban and public health governance. A global commitment to the alleviation of urban poverty is much needed to negate the hazards to child health that will echo into future generations.

Aims Over recent decades there has been unprecedented growth in the urban population, with the sharpest rise occurring in developing countries' youth population. Cities are generally considered to be centres of development with an assumed advantage for health. However, there is seldom a distinction made for disadvantaged or marginalised groups such as the urban poor. Children are particularly vulnerable to urban environmental hazards and those that are born into poverty are disproportionately affected.

Methods This study uses the social determinants of health model to assess the effect of the urban environment on the health outcomes of children of the urban poor. Mumbai, India and Nigeria, Lagos, two of the largest and most rapidly growing cities in the world (see Figure 1), are used as case studies. Their current and projected population growth is almost equivalent to slum growth rate (see Figure 2), this can be seen to represent rising urban poverty and inequity. These trends can be extrapolated to many other cities experiencing the same global forces of urbanisation. 


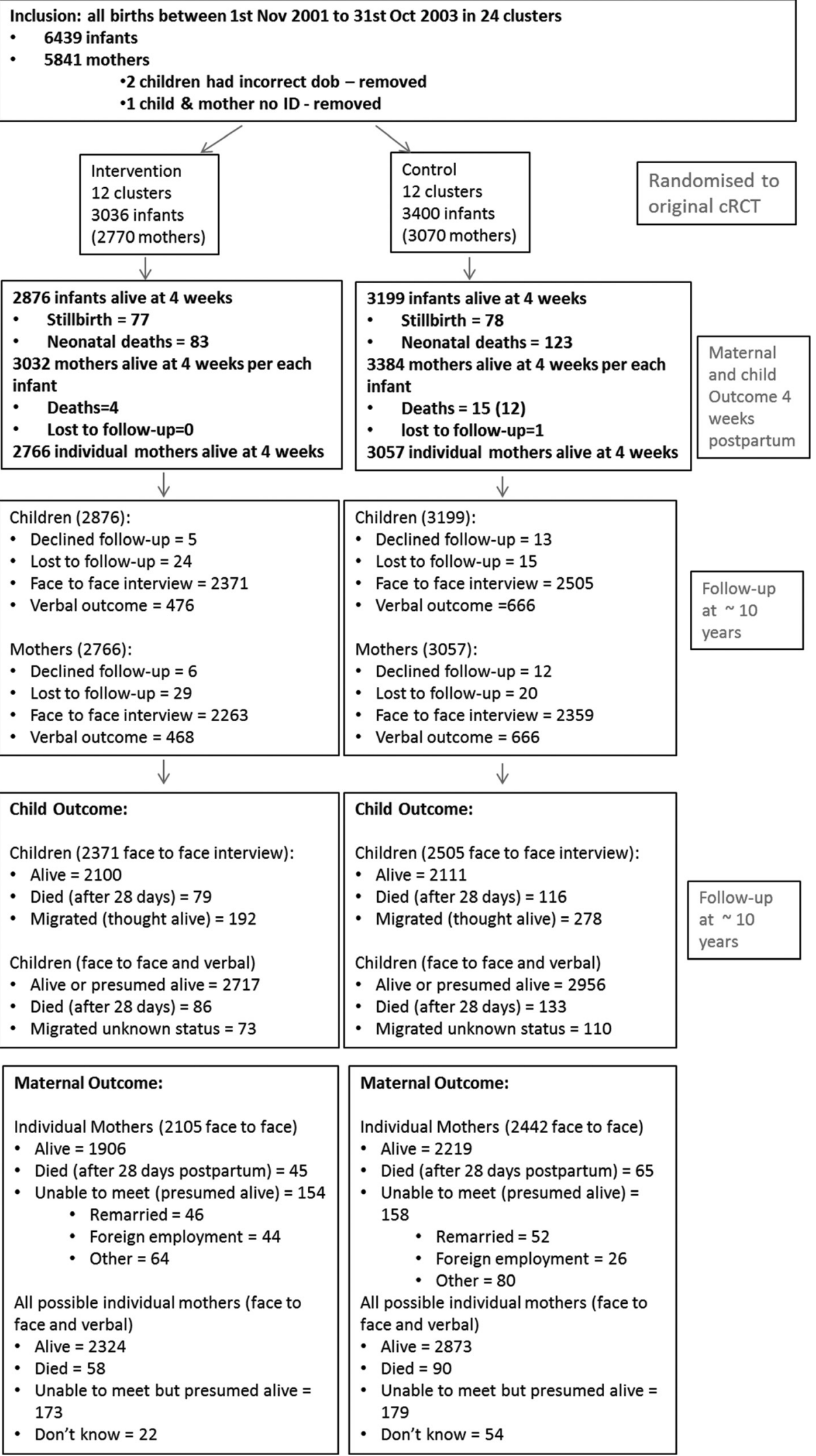

\section{Abstract G248 Figure 1 Outcome data}

Results The urbanisation of poverty is evident in these case studies and is one of the strongest determinants of child health, with rising socio-economic inequality in cities endangering the health of children across many sectors of society. Mean child mortality in urban Nigeria and India is lower than in rural areas (see
Figure 3); however this obscures the outcomes amongst the urban poor. Urban child morbidity, in many cases, is equivalent to or higher than rural rates; this is particularly evident in the urban prevalence of childhood infections and malnutrition, both of which are inextricably related to urban poverty. 